\title{
GERENCIAMENTO DE RISCOS NA CADEIA AGROINDUSTRIAL DE FRANGO: ANÁLISE DA PERSPECTIVA DOS AVICULTORES EM UBÁ, MINAS GERAIS.
}

\section{RISK MANAGEMENT IN THE BROILER AGRO INDUSTRIAL CHAIN: ANALYSIS OF CHICKEN PRODUCERS'PERSPECTIVE IN UBÁ, MINAS GERAIS}

\author{
Leandro Gomes de Oliveira* E-mail: leandrobaquim@yahoo.com.br \\ Denise Cervilha de Freitas* E-mail: decervilha@hotmail.com \\ Mario Otavio Batalha* E-mail: dmob@ufscar.br \\ Rosane Lúcia Chicarelli Alcântara*Email: rosane@dep.ufscar.br \\ *Universidade Federal de São Carlos (UFSCar), São Carlos, SP
}

Resumo: A cadeia de frango é de grande importância para o agronegócio brasileiro. Apesar de utilizar a integração como forma de coordenação de sua cadeia de suprimentos, eventos de riscos são inerentes e podem influenciar seu funcionamento e seu desempenho. Esse estudo visou identificar os riscos que impactam negativamente a cadeia de frango de corte sobre a perspectiva dos avicultores do município de Ubá, Minas Gerais e quais as estratégias adotadas pela agroindústria integradora a fim de mitigá-los. Para isso, realizou-se uma revisão da literatura para identificar os principais riscos inerentes a essa cadeia e depois um questionário foi aplicado para analisar a perspectiva dos avicultores integrados em relação a esses riscos. Em seguida, uma entrevista em profundidade foi realizada para entender as respostas obtidas e identificar as estratégias de mitigação de riscos utilizados por essa cadeia. Foi possível perceber que os riscos mais impactantes na cadeia de suprimentos de frango, na perspectiva dos avicultores, foram aumento da temperatura, preço recebido pelo produtor e risco relacionado ao investimento; e os riscos menos importantes foram condições das estradas, contaminação da ração e aumento do preço da carne de frango. Verificou-se também que alguns dos riscos identificados na pesquisa já possuem estratégias de mitigação, principalmente através da incorporação de novas tecnologias e equipamentos.

Palavras-chave: Gestão de Riscos na Cadeia de Suprimentos. Cadeia de frango de corte. Integração. Estratégias de mitigação de risco. Avicultor.

Abstract: The broiler agro industrial chain is very important for Brazilian agribusiness. Despite employing vertical integration to coordinate its supply chain, risks events are inherent and can influence its operation and performance. This paper aims to identify risks that impact negatively on broiler chain, analyzing the perspective of producers from Ubá City, in Minas Gerais, as well as to identify which strategies are being used in this chain for mitigating them.A literature review to identify the main risks inherent to this chain was executed, followed by the application of a questionnaire answered by the producers. Lastly, an in-depth interview was done to understand the responses and to identify some mitigation strategies adopted in this chain. It was analyzed that more impactful risks in the broiler chain, according to producers' perspective, was temperature increase, price received by the producer and risk related to investment. Less important risks were road conditions, contamination of animal's food and increase in the price of chicken meat. It was also found that many of the risks identified in this research have already mitigation strategies, mainly by the use of new technologies and equipment.

Keywords: Supply Chain Risk Management. Broiler Chain. Integration. Strategies for risk mitigation. Chicken Producer. 


\section{INTRODUÇÃO}

O gerenciamento da cadeia de suprimentos em mercados competitivos tem se tornado uma atividade cada vez mais desafiadora. A globalização, incertezas de mercado, tecnologias inovadoras, ciclo de vida dos produtos mais curtos e aumento dos relacionamentos em redes internacionais têm aumentado os riscos nas cadeias de suprimentos (CHRISTOPHER; LEE, 2004).

Neste contexto, uma área de pesquisa que estuda a mitigação e/ou a eliminação de riscos em cadeia de suprimentos surgiu e vem se consolidando no Brasil e no exterior. A gestão de risco na cadeia de suprimentos é responsável pelo gerenciamento de eventos que podem influenciar negativamente o fluxo de materiais e informações, comprometendo o desenvolvimento e o desempenho das cadeias de suprimentos. O seu principal objetivo é reduzir as perdas ou exposição da cadeia (MANUJ; MENTZER, 2008), melhorar a coordenação e o balanceamento de seus recursos internos e externos, para se tornar mais responsiva e eficiente (MCCORMACK; BRONZO; OLIVEIRA, 2010) garantindo assim, maior lucratividade e a continuidade da cadeia (TANG, 2006).

As cadeias agroindustriais por apresentarem peculiaridades, tais como sazonalidade, variações da qualidade da matéria-prima e perecibilidade da matériaprima e do produto final (BATALHA; SILVA, 2012) são particularmente sensíveis a eventos de riscos. Assim como em outras cadeias, a cadeia agroindustrial de frango é suscetível a riscos que podem trazer grandes perdas e prejuízos financeiros, de material ou de imagem para as empresas. Vale destacar que esta cadeia de produção é de grande importância para o agronegócio e o conjunto da economia brasileira.

A revisão da literatura realizada por Tomas e Alcântara (2013) evidenciou o aumento de estudos sobre Gestão de Riscos em Cadeias de Suprimentos (GRCS) em países desenvolvidos, entretanto pouco explorado no Brasil. Singhal, Agarwal e Mittal (2011), em sua revisão da literatura, também salientaram o crescente interesse no tema e mostraram poucos trabalhos relacionados à área agroindustrial. Desta forma, este estudo exploratório é justificado por se tratar de um assunto em expansão, buscando analisar a GRCS em uma cadeia agroindustrial brasileira. 
Jüttner, Peck e Christopher (2003) listam quatro áreas de pesquisas relacionadas à GRCS, entre elas: avaliação das fontes de riscos na cadeia de suprimentos; definição do conceito de risco em cadeia de suprimentos e suas consequências adversas; identificação dos direcionadores de risco da cadeia de suprimentos e; mitigação de riscos na cadeia de suprimentos. Desta forma, este trabalho busca identificar as possíveis fontes de riscos para a cadeia de suprimentos de frango de corte, sob a ótica dos produtores rurais, além de identificar as estratégias de mitigação desses riscos.

Pretende-se, portanto, gerar conhecimentos sobre os riscos que afetam a cadeia de frango de corte, assim como sobre as estratégias de gestão de risco adotadas por suas agroindústrias processadoras. Espera-se que estas reflexões possam ser úteis para agentes socioeconômicos de produção de frango de corte e também para outras cadeias agroindustriais com dinâmicas competitivas próximas a essa cadeia.

\section{REFERENCIAL TEÓRICO}

Para o desenvolvimento deste estudo foram utilizadas como base teórica as seguintes temáticas: cadeia agroindustrial de frango de corte, sistema de integração e gerenciamento de riscos na cadeia de suprimentos.

\subsection{Cadeia agroindustrial de frango de corte}

O desenvolvimento da avicultura de corte no Brasil ocorreu no final de 1950, na região Sudeste. Posteriormente, em 1970, houve intensa reorganização do complexo agroindustrial de carnes, deslocando a produção para a região Sul (BELUSO; HESPANHOL, 2010; CANEVER et al., 1997; SARCINELLI et al., 2007). Atrelado a isso, ocorreram grandes modificações no sistema produtivo como o alto nível tecnológico e a integração avicultor/agroindústria, que deram maior dinamismo à atividade, colocando-a em posição privilegiada em relação a outras atividades pecuárias no Brasil.

A avicultura de corte é uma das culturas de maior destaque no agronegócio brasileiro. De acordo com o portal eletrônico da Associação Brasileira de Proteína 
Animal (ABPA), ela é responsável por 1,5\% de todo o PIB do país. Em 2011, o Brasil foi o terceiro maior produtor mundial de frango (13,058 milhões de toneladas) e 0 maior exportador (3,918 milhões de toneladas) tendo como destino mais de 150 países do Oriente Médio, Ásia, Europa e Oceania (ABPA, 2014).

As regiões Sul e Sudeste são as maiores produtoras de frango de corte no Brasil. Dessas regiões, os estados brasileiros com maiores produção são o estado do Paraná, responsável por 29,7\% do total, seguido de Santa Catarina, com 17,7\%; Rio Grande do Sul, com 14,4\%; São Paulo, com 12,7\% e Minas Gerais, com 4,63\% da produção nacional. Contudo, há um crescente aumento da produção na região Centro-Oeste do país, devido à proximidade a áreas produtoras de milho e soja, principais componentes da ração de frango (ABPA, 2014).

Segundo Voilà e Triches (2013), a cadeia produtiva de frango é caracterizada por uma sequência de operações que pode ser dividida em três grandes áreas:

i) Produção de insumos: a etapa de produção de insumos compreende os avozeiros, matrizeiros, incubatório e aviários;

ii) Industrialização: a segunda etapa refere-se à industrialização, desenvolvida por uma agroindústria ou frigorífico;

iii) Comercialização e distribuição: a etapa de comercialização/ distribuição compreende empresas atacadistas, redes de supermercados, açougues, varejistas e mercado internacional.

A Figura 1 ilustra os principais elos da cadeia agroindustrial de frango de corte. Nessa cadeia, a agroindústria exerce a função de empresa focal ${ }^{1}$, sendo a principal responsável por coordenar os elos de produção, de matériaprima e distribuição através de sistemas de integração.

1 A empresa focal é aquela que estabelece regras ou governa a cadeia de suprimento, mantém contato direto com o consumidor ou projeta os produtos que a cadeia oferece (Carvalho; Barbieri, 2013). 
Figura 1 - Cadeia Agroindustrial de Frango de Corte

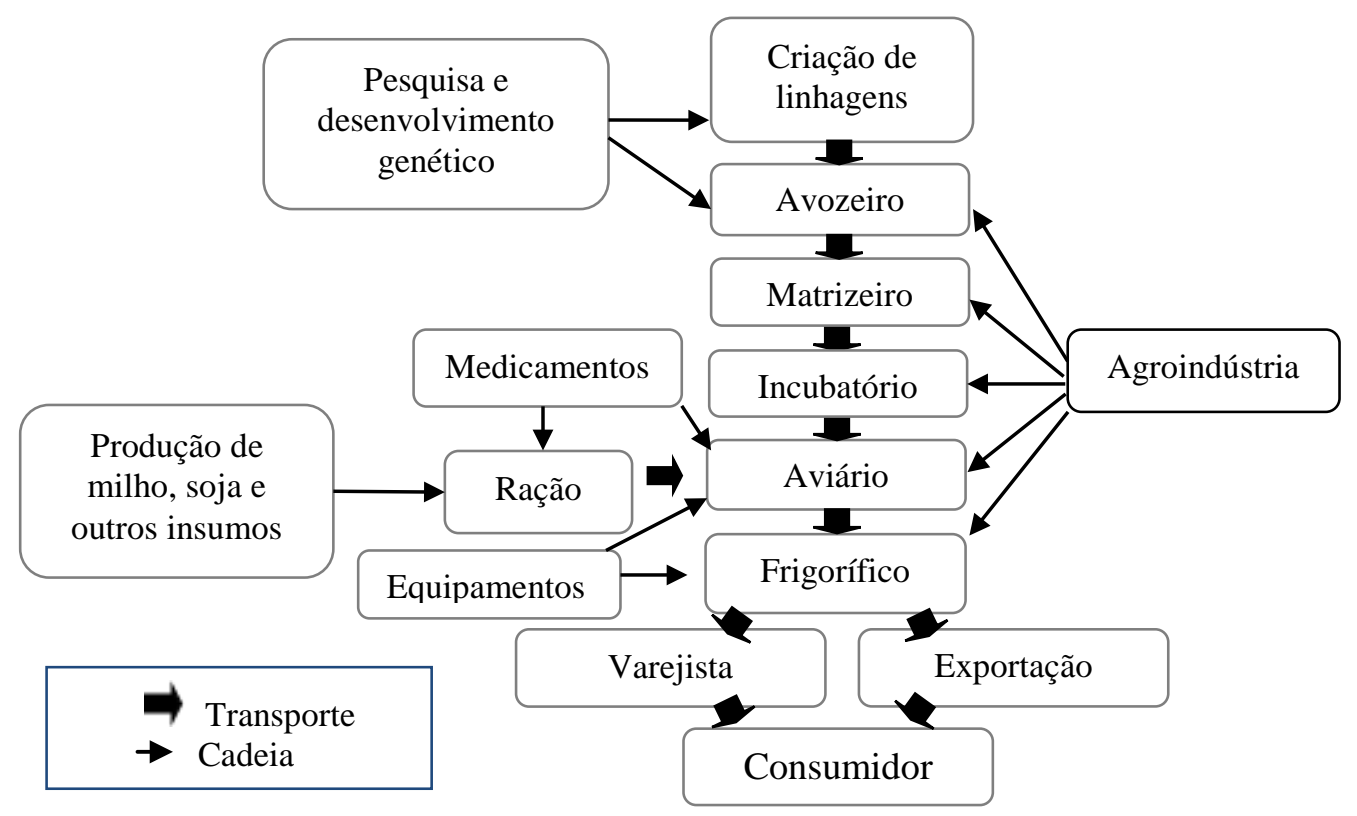

Fonte: Voilà; Triches (2013)

\subsection{Sistema de integração}

Antes do sistema de integração, as atividades na cadeia de frango de corte eram desenvolvidas de forma independente, sendo que os granjeiros eram responsáveis pelo processo de engorda de suas aves, incluindo a aquisição dos insumos necessários; e venda das aves aos frigoríficos, onde eram abatidas. O processo de integração da indústria avícola brasileira iniciou-se a partir da década de 70, no Estado de Santa Catarina, segundo os modelos de governança utilizados nos Estados Unidos. O pioneirismo do Sul do Brasil nesse movimento se deve à oferta de grãos (soja, milho e trigo) que atraíram as indústrias de rações para a região (CARLETTI FILHO, 2005). Estima-se que 90\% da avicultura industrial brasileira operacionalizem por meio do sistema de integração atualmente (ABPA, 2015).

O sistema de integração visa intensificar e padronizar os sistemas produtivos através de parceria entre produtores rurais (integrado) e agroindústria (integradora) (FRANÇA; FERNANDES FILHO, 2003). Carletti Filho (2005) destaca que o termo "integrado" é comumente utilizado para se referir aos produtores responsáveis pelo processo de criação e engorda segundo um contrato de parceria exclusivo. Nesse sistema, a agroindústria se responsabiliza pela boa qualidade dos serviços 
prestados, garantindo o fornecimento de rações, distribuição dos animais e assistência técnica, bem como a retirada dos lotes. Os produtores rurais fornecem as instalações, equipamentos, água e energia e são responsáveis pelo manejo dos animais (criação e engorda), realizando os trabalhos segundo o planejamento estabelecido pela agroindústria (FRANÇA; FERNANDES FILHO, 2003).

Segundo o Relatório Anual da ABEF (2005, p.31), no sistema integrado, "os avicultores recebem orientação das indústrias para: construção e instalação de aviários e equipamentos; treinamento de manejo; ração balanceada, baseada em milho (66\%) e soja (24\%); acompanhamento veterinário; entrega das aves para abate no prazo e peso necessários; escalas de abate e tamanho das aves para diferentes mercados". Esse sistema resulta no "baixo custo de produção; tecnologia, qualidade e inovação no processo produtivo, com rigoroso controle sanitário; empresas com certificação internacional; capacidade de adaptação em relação à demanda por produtos especiais exigidos pelo mercado consumidor".

Este sistema é particularmente interessante para a agroindústria, pois os investimentos em terras, instalações, máquinas e mão-de-obra são transferidos aos produtores rurais, aumentando a competitividade do produto no mercado. Para os produtores rurais, o sistema de integração garante o escoamento da sua produção e assistência técnica, obtenção de melhores insumos de produção, assegura uma produção ininterrupta, propicia maior facilidade de acesso ao crédito e a incorporação mais rápida de inovações tecnológicas (FERREIRA, 2007; GOMES; GOMES, 2008; PÔNZIO, 2007; SILVA, 2006).

De acordo com o censo agropecuário de 2006, havia no Brasil aproximadamente dois milhões de propriedades rurais no país destinadas a criação de aves. Deste total, 21 mil eram voltadas para a produção de frango de corte de forma integrada, sendo que, em Minas Gerais, os contratos têm sido firmados principalmente com agricultores familiares (COSTA et al, 2011).

Desse modo, o sistema de integração sido fundamental para o setor, uma vez que proporciona importantes ganhos de eficiência, gerando competitividade ao setor internacionalmente, além de aumentar a participação no mercado interno de carnes (FARINA, 1995; Ferreira, 2002; ZILLI, 2003). 


\subsection{Gerenciamento de riscos na cadeia de suprimentos}

A Gestão de Riscos em Cadeias de Suprimentos ou Supply Chain Risk Management (SCRM) é resultado da interseção entre as áreas de Supply Chain Management (SCM) e Risk Management (RM) (ZSIDISIN; RITCHIE, 2009) e busca identificar e gerenciar os riscos internos e externos a cadeia de suprimentos permitindo a redução ou a mitigação das suas vulnerabilidades por meio de abordagens coordenadas entre os membros da cadeia (JÜTTNER; PECK; CHRISTOPHER, 2003; RAO; GOLDSBY, 2009). Coerentemente, segundo Singhal, Agarwal e Mittal (2011, p.16), a SCRM "surgiu como uma extensão natural da gestão da cadeia de suprimentos com o objetivo principal de identificar as fontes de risco potenciais e sugerir planos de ação convenientes para mitiga-los".

Para Manuj e Mentzer (2008), a globalização, apesar de oferecer vantagens às cadeias de suprimentos, tais como acesso a mão-de-obra, matéria-prima mais barata, mercados consumidores maiores e oportunidades de financiamento, também aumenta as incertezas e oferece riscos às empresas. O reconhecimento de que uma interrupção em um elo da cadeia de suprimentos pode afetar diretamente a habilidade de uma empresa de continuar suas operações, entregar os produtos finais para o mercado ou fornecer serviços críticos aos seus clientes (JÜTTNER; PECK; CHRISTOPHER, 2003) faz com que as empresas busquem estratégias para a efetiva redução de riscos em suas cadeias (MANUJ; MENTZER, 2008).

Para Dani (2009) e Singhal, Agarwal e Mittal (2011), além da globalização, ambientes de negócios competitivos, o aumento de desastres naturais, foco na eficiência em vez na eficácia, imprecisão das informações, assimetria de poder e a dependência tornam as cadeias de suprimentos suscetíveis a eventos de riscos, que podem causar perdas financeiras, de recursos físicos e humanos, materiais e de imagem para as empresas, ou ainda prejudicar o funcionamento e o desempenho da cadeia de suprimentos.

Analisando as fontes de riscos que podem impactar as cadeias de suprimentos, Christopher e Peck (2004) classificaram-nas em três categorias: interno à empresa focal; externo à empresa focal, mas interno à cadeia; e externo à cadeia. Os riscos internos à empresa focal podem ser divididos em riscos de processos e/ou 
controle. Os riscos de processos são referentes à ruptura das sequências de atividades que adicionam valor ao produto e do gerenciamento da organização. Os riscos de controle são relativos à empregabilidade ou não de regras, sistemas e procedimentos estabelecidos para execução dos processos (CHRISTOPHER; PECK, 2004).

Os riscos externos à empresa focal, mas interno à cadeia estão relacionados a distúrbios potenciais ou reais do fluxo de produto e de troca de informações entre a empresa focal e as empresas a montante e a jusante da cadeia de suprimentos. Geralmente, estão sob o controle do próprio negócio são recorrentes das falhas de interação e cooperação entre as diferentes empresas da cadeia de suprimentos (AGUIAR; TORTARO; GONÇALVES, 2012).

Os riscos externos são aqueles sobre os quais as organizações participantes da cadeia de suprimentos não possuem controle, independentemente das ações estratégias exercidas por elas. Esses riscos são decorrentes das características ambientais onde a cadeia de suprimentos atua. Eles podem ser o resultado de eventos sociopolíticos, macroeconômicos, tecnológicos e climáticos que, mesmo ocorrendo longe das organizações, podem afetá-las negativamente (KERSTEN; HOHRATH; BÖGER, 2007). Dentre eles pode-se citar: condições meteorológicas extremas, desastres naturais, alterações regulamentares, contaminação do produto, crises mundiais, etc.

Assim, as cadeias agroindustriais precisam adotar mecanismos de governança eficientes que propiciem a redução ou eliminação os impactos causados por esses riscos. O sistema de integração utilizado pela cadeia agroindustrial de frango de corte brasileira tem essa característica, uma vez que consegue coordenar melhor o fluxo produtivo, atuando preventivamente em problemas que poderiam interromper o funcionamento e o desempenho da cadeia.

\section{PROCEDIMENTOS METODOLÓGICOS}

A presente pesquisa possui caráter exploratório que, segundo Gil (2008), visa proporcionar maior familiaridade com determinado problema, tornando-o mais explícito. Desta forma, este artigo tem como objetivo identificar as possíveis fontes 
de risco da cadeia agroindustrial de frango de corte por meio da percepção dos avicultores, além de determinar as estratégias de mitigação utilizadas pelos elos da cadeia de suprimentos. A pesquisa exploratória é justificável pelo pequeno número de pesquisas relacionadas à gestão de riscos em cadeias de suprimentos brasileiras em geral (TOMAS; ALCÂNTARA, 2013) e principalmente relacionadas à cadeia agroindustrial (JÜTTNER; PECK; CHRISTOPHER, 2003). A análise da gestão de risco em uma cadeia de suprimentos que utiliza o sistema de integração como forma de coordenação apresenta um grande diferencial desta pesquisa.

Inicialmente foi realizada uma revisão bibliográfica para a identificação dos possíveis riscos que podem afetar o funcionamento da cadeia agroindustrial de frango de corte, conhecimento este que se apresenta de forma muito fragmentada na literatura, dificultando sua identificação pelos profissionais e acadêmicos que trabalham diretamente com essa cadeia. A partir desse levantamento, foram realizadas entrevistas com avicultores para analisar sua percepção em relação a esses riscos. Finalmente, uma entrevista em profundidade com o supervisor da agroindústria responsável pelo acompanhamento e assistência técnica do processo de cria e engorda dos frangos foi realizada para compreender melhor os resultados e também para identificar as estratégias de mitigação utilizadas na cadeia.

A seleção dos avicultores para a pesquisa foi feita de forma intencional e por conveniência, não probabilística (MARCONI; LAKATOS, 1999; FREITAS et al., 2000), uma vez que o objetivo da pesquisa não é a generalização, mas desenvolver maior compreensão do problema pesquisado (GIL, 2008), testando a viabilidade de um estudo mais criterioso (FORZA, 2002).

A população do estudo consiste num total de vinte e um avicultores que residem no município de Ubá-MG, integrados à agroindústria da região. O primeiro contato com esses avicultores foi feito com o intuito de apresentar os objetivos da pesquisa e tentar garantir a participação dos mesmos. Alguns produtores não foram encontrados e outros alegaram indisponibilidade para o preenchimento do questionário, resultando em uma amostra de seis avicultores.

Vale a pena ressaltar que, apesar da pesquisa abordar somente os avicultores de Ubá, estima-se que 90\% da avicultura industrial brasileira operacionalizem por meio do mesmo sistema de integração desse município (ABPA, 
2015). Desse modo, os resultados desse estudo são relevantes, pois abordam um tema totalmente importante para a avicultura brasileira.

Para a coleta de dados foi utilizado um questionário estruturado, dividido em três partes. O objetivo da primeira parte é a identificação dos participantes do estudo através de questões dicotômicas e seus resultados estão expostos na seção 4.2 deste trabalho. A segunda parte busca caracterizar o processo de integração realizado entre a agroindústria e os avicultores. Foram utilizadas questões dicotômicas e seus resultados estão expostos na seção 4.3. Por fim, a última parte é composta por questões relacionadas à ocorrência dos riscos (identificados a partir da revisão bibliográfica) na cadeia de frango de corte, com respostas tipo likert, variando de 1 (discordo totalmente) até 5 (concordo totalmente) e seus resultados estão expressos na seção 4.4.

O questionário foi analisado previamente por dois professores especializados na área de riscos na cadeia de suprimentos e dois estudantes de mestrado em engenharia de produção interessados nessa temática. Além disso, dois profissionais da cadeia de frango de corte analisaram o conteúdo do questionário buscando identificar as possíveis inconsistências e ambiguidades a fim de torná-lo mais compreensível. O questionário foi aplicado entre dezembro de 2013 e janeiro de 2014. Finalmente, a entrevista em profundidade foi aplicada por meio de um questionário semiestruturado em fevereiro de 2014, seguindo a mesma lógica do questionário aplicado inicialmente, baseado nas dúvidas levantadas a partir da análise das respostas dos entrevistados.

Para a análise dos dados do questionário estruturado, utilizou-se a estatística descritiva baseando-se em cálculo da moda da amostra.

\section{DESCRIÇÃO E ANÁLISE DOS RESULTADOS}

Nesta seção serão descritos e analisados os principais resultados obtidos na pesquisa. Estes estão organizados em quatro subseções. Na primeira subseção são apresentados os riscos da cadeia de frango de corte, de acordo com a revisão bibliográfica. $\mathrm{Na}$ segunda são apresentadas as principais características dos avicultores participantes do estudo. Na terceira são descritas as atividades 
realizadas pela agroindústria relacionadas ao processo de integração. Finalmente, os cálculos estatísticos relacionados aos riscos identificados pelos produtores são apresentados na quarta subseção.

\subsection{Riscos na cadeia agroindustrial de frango de corte}

Os eventos que impactam negativamente na cadeia de frango podem ser provenientes do ambiente interno ou externo a cadeia, conforme classificação de Christopher e Peck (2004). Dentre esses, pode-se citar:

\subsubsection{Riscos internos à empresa focal}

Infraestrutura de produção: A infraestrutura não condizente com as especificações, como problemas de maquinário, falta de equipamento, obsolescência de máquinas e de equipamentos podem ocasionar prejuízos ou perdas para as cadeias produtivas (LARA, 2010).

\subsubsection{Riscos externos à empresa focal, porém internos a cadeia}

Excesso de animais no galpão: O aumento do número de animais nos galpões pode comprometer a conversão alimentar dos animais ocasionando prejuízos para o produtor e para a agroindústria (União Brasileira de Avicultura UBA, 2008);

Contaminação da ração: produtos contaminados ou toxinas nas matériasprimas utilizadas na fabricação da ração estão entre as principais preocupações da cadeia avícola (JESUS JR. et al., 2007);

Risco relacionado ao investimento: $\mathrm{Na}$ integração, os produtores arcam com os investimentos para a construção do galpão. Atualmente, um galpão com capacidade para 30.000 frangos custa $\mathrm{R} \$ 385.000,00$. Para isso, o avicultor pode utilizar de linhas de crédito do PRONAF, porém o retorno do capital não é garantido (AGROMARAU, 2014); 
Preço recebido pelo avicultor: O valor pago ao avicultor é calculado com base na quantidade de animais no galpão, quantidade de ração consumida, taxa de mortalidade e conversão alimentar (ganho de peso/ração consumida). O produtor rural não tem acesso aos mecanismos de precificação dos frigoríficos e também não participa da pesagem e da contagem dos animais que entrega a estas empresas (AVIZOM, 2014);

Aumento do preço da carne de frango: O aumento do preço do quilo da carne de frango pode ocasionar a substituição desta por outros tipos de carnes como bovina ou suína.

\subsubsection{Riscos Externos à cadeia}

Transmissão de doenças: doenças como a de Newcastle e de Marek, bouba aviária, estafilocose, ornitose, salmonelose, coriza infecciosa, gripe aviária podem prejudicar o desenvolvimento e levar a perda de muitos animais (ACERC, 2014);

Linhagens menos resistentes: As linhagens menos resistentes são aquelas que possuem conversão alimentar baixa. Elas estão mais suscetíveis à transmissão de doenças e propensas a morte (MORAES; CAPANEMA, 2012);

Greves trabalhistas: greves são fatores de riscos que podem interromper a produção nos abatedouros, frigoríficos e agroindústrias. As consequências seriam a falta de distribuição da ração para os avicultores e a redução da capacidade de abate dos animais (MARQUES; FARIA; SOUZA, 2011);

Problemas na rede elétrica: A energia é imprescindível à produção de frango, pois os maquinários e equipamentos são operados a base de energia elétrica. Problemas de abastecimento de eletricidade pode comprometer todo o fornecimento de matéria-prima;

Condições das estradas: as condições precárias das estradas brasileiras geram grandes perdas para todo o agronegócio, além de aumentar os custos e reduzir a competitividade dos produtos brasileiros no exterior (FLEURY, 2005);

Aumento da temperatura: na cadeia de frango, um fator de risco é a temperatura do ambiente. No início do processo de engorda dos animais, até o sétimo dia, a temperatura no galpão deve estar em torno de $32^{\circ} \mathrm{C}$. No entanto, no 
decorrer do processo, a temperatura precisa ser controlada a níveis mais baixos. Para isso, utilizam-se climatizadores e ventiladores, que amenizam a sensação térmica dentro do galpão (UBA, 2008).

\subsection{Descrição dos avicultores}

A descrição dos avicultores que responderam ao questionário é apresentada na Tabela 1, a partir do número de galpões, capacidade de produção/lote, tempo de relação com a agroindústria e o número de empregados.

Tabela 1 - Descrição dos avicultores participantes da pesquisa

\begin{tabular}{ccccc}
\hline Produtor & $\begin{array}{c}\text { Número de } \\
\text { Galpões }\end{array}$ & $\begin{array}{c}\text { Capacidade de } \\
\text { produçãollote }\end{array}$ & $\begin{array}{c}\text { Tempo de relação } \\
\text { com a agroindústria } \\
\text { (anos) }\end{array}$ & $\begin{array}{c}\text { Número de } \\
\text { empregados }\end{array}$ \\
\hline A & 1 & 15.000 & 20 & 0 \\
B & 2 & 30.000 & 25 & 1 \\
C & 2 & 60.000 & 5 & 2 \\
D & 3 & 45.000 & 15 & 0 \\
E & 3 & 90.000 & 5 & 3 \\
F & 1 & 15.000 & 10 & 0 \\
\hline
\end{tabular}

Fonte: Pesquisa de campo

A Tabela 1 mostra que a maioria dos avicultores é integrada a agroindústria há um longo período de tempo. Isso facilita o relacionamento e proporciona benefícios, tanto para a agroindústria como para o avicultor. Pode-se evidenciar também, que quatro dos avicultores ( $A, B, D$ e $F$ ) possuem galpões com capacidade produtiva de 15.000 frangos/lote. Esses são galpões que obedecem às regras $e$ procedimentos determinados pelos contratos de integração antigos, sendo a capacidade máxima produtiva por galpão/lote de 15.000 frangos. No entanto, nos novos contratos estipulados pela agroindústria, essa capacidade passa a ser de 30.000 frangos/galpão. Além disso, metade dos entrevistados possui empregados para desenvolvimento de suas atividades e a outra metade opera somente com mão de obra familiar. 


\subsection{Descrição das atividades realizadas pela agroindústria no processo de integração}

Todos os avicultores entrevistados informaram que a agroindústria não promove treinamentos antes ou após iniciadas a integração. Isso pode causar falhas no sistema de produção, podendo gerar perdas para cadeia. Além disso, todos os respondentes também alegaram que principal sistema de informação utilizado para manter contato com a agroindústria ocorre por meio de ligações telefônicas.

Em relação à assistência técnica, segundo os respondentes, a visita de zootécnicos ou veterinários ocorre semanalmente, mas, caso ocorra imprevistos, essa visita pode ocorrer sempre que for necessário.

Dos respondentes, 2/3 alegaram não possuir todos os equipamentos $\mathrm{e}$ maquinários necessários para desenvolver o manejo (cria e engorda) dos animais, uma vez que representam um alto valor de aquisição, não condizente com a renda recebida pelos avicultores. No entanto, os avicultores sofrem grande pressão da agroindústria para se adequarem as normas de produção. Com isso, os avicultores se endividam, para não sofrer penalidades ou ter seu contrato encerrado.

\subsection{Identificação dos riscos}

Através de estatística descritiva verificou-se os riscos, citados na seção 4.1, que mais influenciam a cadeia de suprimentos de carne de frango (a partir da perspectiva dos avicultores) e podem gerar grandes prejuízos e perdas. Os riscos abordados na pesquisa com as respectivas modas são apresentados no Gráfico 1.

Analisando a moda obtida para cada fonte de risco, pode-se determinar quais os riscos são mais e menos impactantes. Para isso, essa moda foi confrontada com o centro da escala Likert de resposta (3), ou seja, os riscos mais impactantes são aqueles cuja moda é maior que três e os riscos com menor impacto são aqueles com moda menor ou igual a três. Desse modo, é possível perceber que os riscos mais impactantes para a cadeia de produção de frango são aumento da temperatura, preço recebido pelo produtor, risco relacionado ao investimento, linhagens menos resistentes, problemas na rede elétrica, transmissão de doenças, 
excesso de animais no galpão e infraestrutura de produção. Por outro lado, greves trabalhistas, aumento do preço da carne de frango, contaminação da ração e condições das estradas não são percebidas pelos avicultores como impactantes na cadeia de suprimentos de frango.

Gráfico 1 - Percepção dos avicultores sobre as fontes de risco

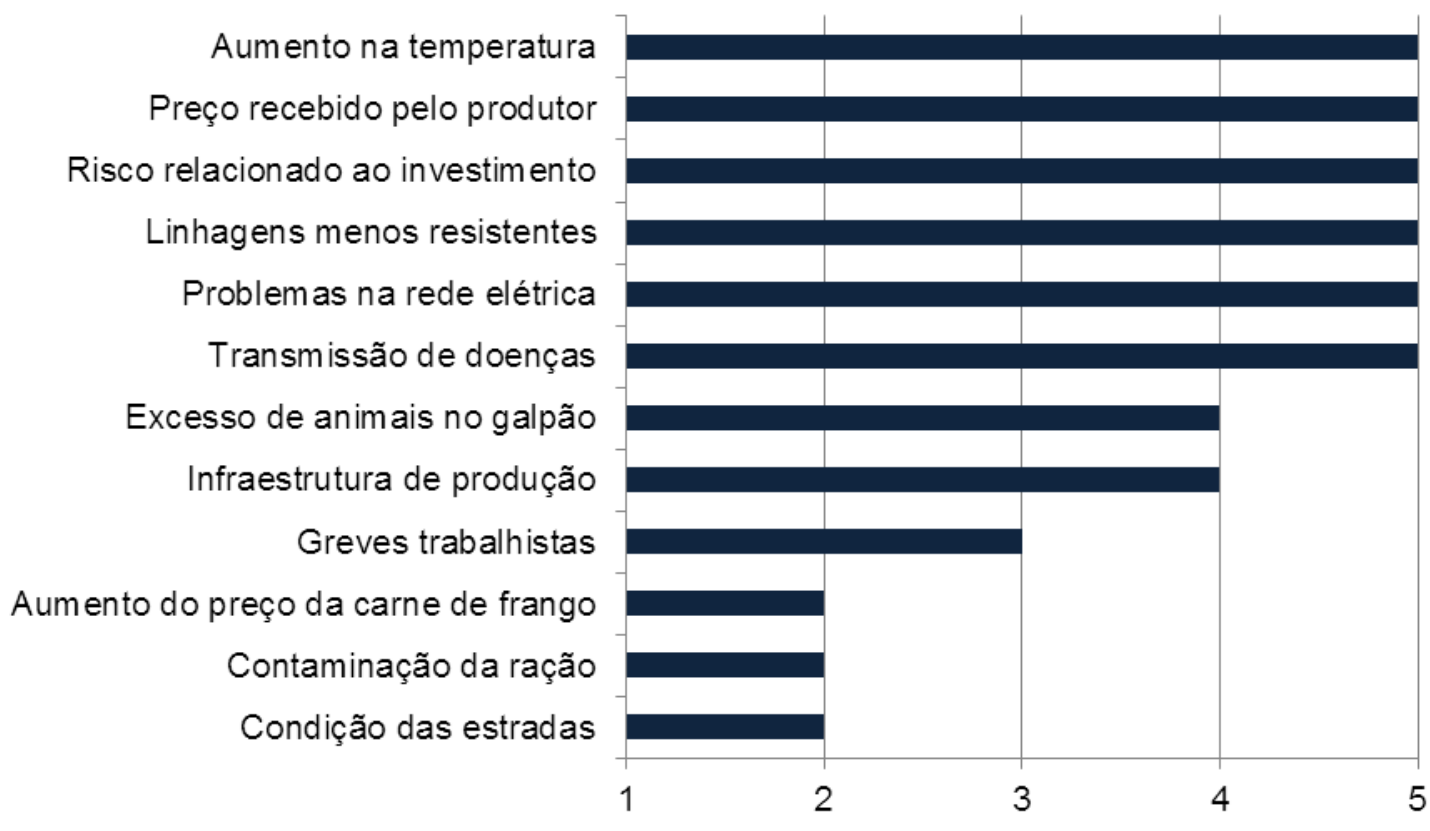

Fonte: Pesquisa de campo

As estratégias de mitigação de riscos são as atividades voltadas especificamente para prevenir e/ou eliminar as possíveis ameaças na cadeia de suprimentos. Em entrevista com o supervisor da agroindústria, ele ressaltou que a empresa em que trabalha não possui um departamento específico de mitigação de riscos. Porém, a modernização tecnológica que vem ocorrendo no setor nos últimos anos, além de buscar ganhos de produtividade, visa amenizar a incidência de riscos na cadeia. O Quadro 1 apresenta os riscos analisados no estudo e as principais estratégias de mitigação obtidas a partir da entrevista em profundidade. 
Quadro 1 - Fontes de risco e suas principais estratégias de mitigação

\begin{tabular}{|l|l|}
\hline \multicolumn{1}{|c|}{ Risco } & \multicolumn{1}{c|}{ Estratégia de mitigação } \\
\hline $\begin{array}{l}\text { Aumento da temperatura no } \\
\text { galpão }\end{array}$ & Uso de ventiladores e climatizadores \\
\hline Problemas na rede elétrica & Aquisição de geradores de energia \\
\hline Transmissão de doenças & $\begin{array}{l}\text { Vacinas mais eficientes e isolamento do galpão a outros } \\
\text { animais }\end{array}$ \\
\hline Excesso de animais no galpão & Aumento dos contratos de integração \\
\hline Infraestrutura de produção & Vistoria aos equipamentos e fatores de produção \\
\hline Greves trabalhistas & $\begin{array}{l}\text { Melhoria das condições trabalhistas e atendimentos das } \\
\text { reivindicações sindicais }\end{array}$ \\
\hline Contaminação da ração & Rastreabilidade da matéria-prima \\
\hline Condições das estradas & $\begin{array}{l}\text { Contratos de integração mais rigorosos que estipulem que o } \\
\text { integrado tenha a obrigação de manter as estradas de } \\
\text { acesso transitáveis }\end{array}$ \\
\hline
\end{tabular}

Fonte: Pesquisa de campo

A partir da entrevista em profundidade com o supervisor da agroindústria, não foi possível, entretanto, identificar estratégias específicas de mitigação dos riscos relacionados ao preço recebido pelo produtor, risco relacionado ao investimento, aumento do preço da carne de frango, linhagens menos resistentes e aumento do preço da carne de frango.

\section{CONSIDERAÇÕES FINAIS}

A cadeia agroindustrial de frango de corte é de grande importância para o agronegócio brasileiro. Esta, por sua natureza, é suscetível a riscos que podem trazer grandes prejuízos financeiros, materiais, ou de imagem para todos os seus agentes. O gerenciamento de risco na cadeia de suprimentos foi criado na tentativa de mitigar ou eliminar os eventos internos e externos a cadeia de suprimentos que possam prejudicar seu funcionamento e seu desempenho.

Esta pesquisa buscou identificar os principais riscos inerentes à cadeia de frango de corte. Através da revisão da literatura, foi possível elencar os principais riscos que podem afetar essa cadeia. Posteriormente, foram consultados avicultores de Ubá-MG e integrados à agroindústria da região, os quais apontaram através da 
percepção, os riscos com maior incidência na cadeia agroindustrial de frango de corte. Finalmente, foi realizada uma entrevista em profundidade com um dos avicultores pra melhor entendimento do resultado da pesquisa e para identificar as principais estratégias adotadas pela agroindústria para a mitigação dos riscos investigados.

A pesquisa contribui para a área de gestão de riscos na cadeia de suprimentos mostrando o comportamento de uma cadeia que utiliza a integração como estratégia para manter-se competitiva no mercado e atender de maneira eficaz e eficiente o consumidor final. Além disto, a identificação das fontes de riscos na cadeia de suprimentos da carne de frango contribui para os profissionais desse setor na elaboração de estratégias que evitem que eventos não esperados afetem o comportamento normal da cadeia.

Apesar disto, esta pesquisa apresenta limitações, provenientes principalmente do caráter exploratório da pesquisa. Um ponto a ser destacado é a influência da perspectiva dos avicultores nos resultados encontrados. Eles podem ter respondido com base na influência que os fatores de riscos têm para o seu negócio ou, de outra forma, consideram como mais importantes aqueles riscos que afetam mais diretamente a sua atividade produtiva. Por exemplo, o aumento do preço da carne de frango não foi classificado como relevantes na pesquisa, uma vez que a agroindústria que gerencia a venda da carne de frango, sendo o produtor responsável somente pelo manejo dos animais, tendo sua produção direcionada exclusivamente à agroindústria. Similarmente, as questões como aumento da temperatura, preço recebido pelo produtor, riscos relacionados ao investimento foram percebidas como impactantes na cadeia de produção, uma vez que interferem diretamente em suas atividades produtivas.

Pesquisas futuras podem verificar o impacto causado pela a incidência desses riscos e também englobar a percepção da agroindústria em relação aos fatores de risco, buscando assim abordar as vulnerabilidades inerentes a toda a cadeia de frango de corte. Além disto, as perguntas do questionário podem ser revistas para melhor entendimento das mesmas pelos entrevistados, utilizando outros construtos para identificação de outras fontes de risco. 


\section{REFERÊNCIAS}

ABPA 2014- Associação Brasileira de Proteína Animal. A avicultura Brasileira. São Paulo, 2014. Disponível em:

$<$ http://www.ubabef.com.br/a avicultura brasileira/historia da avicultura no brasil>.

Acesso em: 15 set. 2014.

ABPA - Associação Brasileira de Proteína Animal. Sistema de Integração. São Paulo, 2015. Disponível em:

<http://www.ubabef.com.br/a avicultura brasileira/sistema de integracao >. Acesso em: 24 mai. 2015.

ABEF - Associação Brasileira dos Produtores e Exportadores de Frangos. Relatório Anual 2004. São Paulo, 2005. Disponível em:

<http://www.usjt.br/arq.urb/arquivos/abntnbr6023.pdf>. Acesso em: 24 mai. 2015.

ACERC - Associação dos Criadores e Expositores de Raças Combatentes do Estado de São Paulo. São Paulo, 2014. Disponível em: <http://www.acercsp.org/doencas.htm>. Acesso em: 6 jan. 2014.

AGROMARAU - Rio Branco Equipamentos para Aves e Suínos. Orçamentos para construção de galpões de frango. Ubá, Minas Gerais, 2014. (Orçamento Comercial)

AGUIAR, E. C.; TORTATO, U.; GONÇALVES, M. A. Riscos e gestão de riscos em cadeia de suprimentos: uma síntese da literatura. Revista Espacios, v. 33, n.8, 2012. Disponível em: <http://www.revistaespacios.com/a12v33n08/12330803.html>. Acesso em: 25 mai. 2015.

AVIZOM - Associação de Avicultores da Zona da Mata. Diretoria da AVIZOM e PIF-PAF confirmam aumento de 7,94\% no valor do ponto. Visconde do Rio Branco, MG, 2014. (Comunicado 001/2014).

BATALHA, M. O.; SILVA, A. L. Gerenciamento de sistemas agroindustriais: definições, especificidades e correntes metodológicas. In: BATALHA, M. O. (Coord.) Gestão

Agroindustrial. São Paulo: Atlas, 2012. Cap.1, p.1-62.

BELUSO, D.; HESPANHOL, A. N. A evolução da avicultura industrial brasileira e seus efeitos territoriais. Revista Percurso - NEMO, Maringá, v. 2, n. 1, p. 25-51, 2010.

http://dx.doi.org/10.4025/revpercurso.v2i1.9855

CANEVER et al./Embrapa. A cadeia produtiva do frango de corte no Brasil e Argentina. EMBRAPACNPSA, 1997. 150p. (EMBRAPA-CNPSA. Documentos, 45). Concórdia, SC. 1997.

CARLETTI FILHO, P. D. T. Divisão De Custos E Alinhamento Estratégico De Uma Cadeia De Suprimentos Integrada Verticalmente: O Caso Do Frango Brasileiro. 2005. 156f. Dissertação (Mestrado em Economia Aplicada). Escola Superior de Agricultura Luiz de Queiroz, Universidade de São Paulo, 2005.

CARVALHO, A. P.; BARBIERI, J. C. Inovações socioambientais em cadeias de suprimento: um estudo de caso sobre o papel da empresa focal. Revista de Administração e Inovação, São Paulo, v. 10, n. 1, p.232-256, 2013. http://dx.doi.org/10.5773/rai.v1i1.1109 
CHRISTOPHER, M.; LEE, H. Mitigating supply chain risk through improved confidence. International Journal of Physical Distribution \& Logistics, v. 34, n.5, p.388-396, 2004. http://dx.doi.org/10.1108/09600030410545436.

CHRISTOPHER, M.; PECK, H. Building the resilient supply chain. The International Journal of Logistics Management, v.15, n.2, p.1-13, 2004.

http://dx.doi.org/10.1108/09574090410700275.

COSTA et al. A aplicação do método FMEA e suas implicações no planejamento de uma empresa rural: estudo de caso da granja Oliveira. Revista Produção Online, v.11, n. 3, pp. 757-778, 2011. http://dx.doi.org/10.14488/1676-1901.v11i3.765

DANI, S. Predicting and managing supply chain risk. In: ZSIDISIN G. A.; RITCHIE, B. (Eds.), Supply Chain Risk - A Handbook of Assessment, Management and Performance. New York: Springer, 2009. Cap. 4, p. 53-66.

FARINA, E. Q. M. Sadia: a liderança pela inovação. Revista de Administração, São Paulo, v. 30, n.1, p. 97-106, 1995.

FERREIRA, G. C. Gerenciamento da cadeia de suprimentos: formas organizacionais na cadeia bovina no Rio Grande do Sul. 2002. 217 f. Tese (Doutorado em Administração) - Curso de Pós Graduação em Administração. Universidade do Rio Grande do Sul, 2002.

FERREIRA, C. H. Sistema de integração de aves como modelo de produção para acesso de pequenos e médios produtores. In: Seminário de Aves e Suínos - AveSui Regiões, 2007 Belo Horizonte, 2007. Anais... Belo Horizonte, MG, Brasil, 2007.

FLEURY, P. F. A infra-estrutura e os desafios logísticos das exportações brasileiras. Revista Tecnologística, v. 10, n. 113, p. 70-75, 2005. Disponível em: $<$ http://www.tecnologistica.com.br/tipo revista/do-rio-a-hidrovia-um-longo-caminho-apercorrer-2/>. Acesso em: 12 ago. 2013.

FORZA, C. Survey research in operations management: a process-based perspective. International Journal of Operations and Production Management, v. 22, n. 2, p. 152194, 2002. http://dx.doi.org/10.1108/01443570210414310.

FRANÇA, L. R.; FERNANDES FILHO, J. F. A evolução da avicultura de corte em Goiás. In: PEREIRA, S. L.; XAVIER, C. L. (Orgs). O Agronegócio nas terras de Goiás. Editora UFU, Uberlândia, 2003, 341p.

FREITAS, H. et al. O método de pesquisa survey. Revista de Administração, São Paulo, v. 35, n. 3, pp. 105-112, 2000. Disponível em: <http://www.rausp.usp.br/busca/artigo.asp?num artigo=269>. Acesso em: 14 set. 2013. GIL, A. C. Como elaborar projetos de pesquisa. $4^{\circ}$ ed. São Paulo, Atlas. 2008.

GOMES, A. P. W.; GOMES, A. P. Sistema de integração na avicultura de corte: um estudo de caso na região de Viçosa-MG. In: Congresso da Sociedade Brasileira de Economia, Administração e Sociologia Rural, 46, 2008, Rio Branco. Anais... Rio Branco, 2008.

JESUS JR. et al. A cadeia de carne de frango: tensões, desafios e oportunidades. BNDES Setorial, n. 26, p. 191-232, Rio de Janeiro-RJ, 2007. 
JÜTTNER, U.; PECK, H.; CHRISTOPHER, M. Supply Chain Risk Management: Outlining an Agenda for Future Research. International Journal of Logistics: Research and

Applications, v. 6, n. 4, p. 197-210, 2003.

http://dx.doi.org/10.1080/13675560310001627016.

KERSTEN, W.; HOHRATH, P.; BÖGER, M. An Empirical Approach to Supply Chain Risk Management: Development of a Strategic Framework. Proceeding Production and Operation Management Society Conference, p.1-20, 2007. Disponível em:

$<$ http://www.pomsmeetings.org/ConfProceedings/007/CDProgram/Topics/full length papers files/007-0507.pdf>. Acesso em: 25 mai. 2015.

LARA, M. A. M. Processo de produção de ração. Engormix, Avicultura, Administração, 2010. (Artigos Técnicos). Disponível em: <http://pt.engormix.com/MA-

avicultura/administracao/artigos/producao-de-racao-t331/124-p0.htm>. Acesso em: 12 ago. 2013.

MARQUES, I. C.; FARIA, S. S.; SOUZA, E. M. S. Produção integrada de frango de corte: uma análise SWOT do modelo de gestão adotado por produtores da microrregião de Anápolis-GO. Revista de Administração, São Paulo, n.6, 2011. Disponível em:

$<$ http://revistas.unievangelica.edu.br/index.php/administracao/article/download/371/372>. Acesso em: 10 mai. 2015.

MANUJ, I.; MENTZER, J. T. Global supply chain management strategies. International Journal of Physical Distribution \& Logistics Management. v. 38, n. 3, pp. 192-223, 2008. http://dx.doi.org/10.1108/09600030810866986.

MARCONI, M. A; LAKATOS, E. M. Técnicas de pesquisa. 4. ed. São Paulo: Atlas, 1999. McCORMACK, K.; BRONZO, M.; OLIVEIRA, M. P. V. Uma abordagem probabilística para a avaliação de riscos em cadeias de suprimento. Revista Produção Online, v.10, n.3, pp. 577-598. http://dx.doi.org/10.14488/1676-1901.v10i3.294.

MORAES, V. G.; CAPANEMA, L. A genética de frangos e suínos - a importância estratégica de seu desenvolvimento para o Brasil. Rio de Janeiro: BNDES Setorial, $\mathrm{n}$. 35, pp. 119-154, 2012.

PÔNZIO, J. Notas de Aula da Disciplina de Agronegócio. Faculdade de Viçosa -FDV, 2007.

RAO, S.; GOLDSBY, T. J. Supply chain risks: a review and typology. The International Journal of Logistics Management, v. 20, n.1, p. 97-123, 2009.

http://dx.doi.org/10.1108/09574090910954864.

SARCINELLI; M. F.; VENTURINI; K. S.; SILVA, L. C. Produção de Frango de Corte. Universidade Federal do Espírito Santo - UFES. Boletim Técnico, 2007

SILVA, L. C. Integração vertical contratual no agronegócio: um estudo no complexo agroindustrial da mandioca em Deodápolis, MS. 2006. 120f. Dissertação (Mestrado em Engenharia de Produção) - Curso de Pós Graduação em Engenharia de Produção. Universidade Metodista de Piracicaba.

SINGHAL, P.; AGARWAL, G.; MITTAL, M. L. Supply chain risk management : review, classification and future research directions. International Journal of Business Science and Applied Management, v. 6, n. 3, p. 15-42, 2011. 
TANG, C. S. Robust strategies for mitigating supply chain disruptions. International Journal of Logistics: Research and Applications, v. 9, n.1, p.33-45, 2006. http://dx.doi.org/10.1080/13675560500405584.

TOMAS, R. N.; ALCÂNTARA, R. L. C. Modelos para gestão de riscos em cadeias de suprimentos: revisão, análise e diretrizes para futuras pesquisas. Revista Gestão da Produção, v. 20, n. 3, p. 695-712. http://dx.doi.org/10.1590/S0104-530X2013000300014.

UBA - UNIÃO BRASILEIRA DE AVICULTURA. Protocolo de Boas Práticas de Produção de Frangos, São Paulo, SP, 2008. (Informativo Técnico). Disponível em:

$<$ http://www.avisite.com.br/legislacao/anexos/protocolo de boas praticas de producao de frangos.pdf>. Acesso em: 04 out. 2013.

VOILÀ, M.; TRICHES, D. A cadeia de carne de frango: uma análise dos mercados brasileiros e mundial de 2002 a 2010 (Texto no 44), Caxias do Sul, RS, Centro de Ciências Econômicas, Contábeis e Comércio Internacional, Universidade de Caxias do Sul, Instituto de Pesquisas Econômicas e Sociais (IPES) 2013. Disponível em:

<https://www.ucs.br/site/midia/arquivos/TD 44 JAN 2013 1.pdf>. Acesso em: 30 set. 2013

ZILLI, J. B. Os fatores determinantes para a eficiência econômica dos produtores de frango de corte: uma análise estocástica. 2003. 154f. Dissertação (Mestrado em Economia)- Curso de Pós- Graduação em Economia Aplicada, Escola Superior de Agricultura, 2003.

ZSIDISIN, G. A.; RITCHIE, B. Supply chain risk management - developments, issues and challenges. In G. A. Zsidisin, B. Ritchie (Eds.), Supply Chain Risk - A Handbook of

Assessment, Management and Performance. New York: Springer, 2009. Cap. 1, p. 1-12.

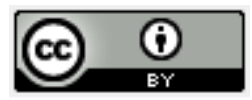

Artigo recebido em 06/11/2014 e aceito para publicação em 31/10/2015 DOI: http://dx.doi.org/ 10.14488/1676-1901.v15i4.1908 